\title{
ARTICLE \\ Characterization of barley germplasm for leaf stripe (Pyrenophora graminea) resistance based on incidence and severity param- eters
}

\author{
Arabi M.I.E.*, Jawhar M. and Al-Shehadah E. \\ Department of Molecular Biology and Biotechnology, AECS, Damascus, Syria.
}

\begin{abstract}
Barley leaf stripe (BLS) caused by Pyrenophora graminea is an important seed-borne disease of barley causing significant yield and quality losses worldwide. The development of resistant cultivars has proven difficult, therefore, in this work, BLSresistant barley germplasm was developed by crossing six barley cultivars currently used in Europe and West Asia. Out of 270 doubled haploid lines derived from these crosses, 40 lines were evaluated under field artificial infection conditions using incidence ( $I$; proportion of diseased plants) and severity ( $S$; proportion of infected leaf area per plant). Disease resistance parameters showed a broad range of variation in mean / and $S$ values with a continuum of resistance levels ranging from highly susceptible to highly resistant with values being consistently higher in the susceptible ones. However, eight promising resistant lines with high yield per plant were identified. Moreover, BLS severity increased linearly as incidence increased $(r=0.76, P<0.001)$. This work suggests that BLS resistance sources identified in this study can be used for further genetic analysis and introgression for varietal improvement, and that the positive correlation between $I$ and $S$ parameters may be beneficial for many types of studies on this disease.

Acta Biol Szeged 63(2):113-118 (2019)
\end{abstract}

\author{
KEY WORDS \\ barley \\ Hordeum vulgare L. \\ incidence \\ leaf stripe \\ severity \\ ARTICLE INFORMATION \\ Submitted \\ 03 December 2019 \\ Accepted \\ 02 February 2020 \\ *Corresponding author \\ E-mail: ascientific@aec.org.sy
}

\section{Introduction}

Leaf stripe caused by Pyrenophora graminea Ito \& Kuribayashi [anamorph Drechslera graminea (Rabenh. ex. Schlech. Shoem)] is a seed-borne disease of barley (Hordeum vulgare L.) found worldwide (Mathre 1997). The fungus can infect barley plants during seed germination, and hyphae accelerate its intercellular growth within the coleorhizae, the embryo, the roots and scutellar node, in order to establish a full-scale infection in the seedling (Platenkamp 1976; Arabi and Jawhar 2005). In susceptible plants, the disease causes severe stunting, premature death, and complete loss of grain (Çelik et al. 2016).

The development of resistant cultivars is the most economic, reliable and environmentally safe way to control leaf stripe (Nielsen 2012; Benkorteby-Lyazidi et al. 2019), especially in developing countries where most farmers are small to marginal and unable to afford costly fungicides and other technologies. In Syria, sources of complete resistance to BLS have not been identified, and current barley cultivars are only moderately resistant toward this disease (Arabi et al. 2004). However, both incidence (proportion of diseased plants) and severity (proportion of plant surface showing symptoms) are the commonly used measures to estimate BLS disease. However, incidence is a measure of diseased or not diseased, this makes it easier and reproducible to measure than severity. In addition, severity is considered to be more important and useful measure than incidence for setting the effectiveness of disease management planning (Campbell and Madden 1990). Consequently, a quantitative relationship between incidence and severity would greatly facilitate the evaluation of disease intensity when accurate assessments of severity are not available or possible (Arabi and Jawhar 2010; Carisse et al. 2013).

As part of a large breeding program from Syriato develop barley varieties with resistance to BLS, hundreds of accessions including landraces, advanced breeding lines, and elite barley varieties were screened. Here we report five crosses of barley cultivars presently grown in Europe and West Asia to screen barley breeding lines for resistance to BLS disease through incidence and severity parameters under Syrian field conditions which is typical of Mediterranean environments. 
Arabi et al.

Table 1. Parental cross and progeny susceptibility to BLS (Pyrenophora graminea)*

\begin{tabular}{llllll}
\hline \multirow{2}{*}{ Cross } & \multicolumn{3}{c}{ Progeny } \\
\cline { 2 - 6 } & Highly resistant & Resistant & Moderately resistant & Susceptible & Highly susceptible \\
\hline Arabi Abiad X IC-9 & 1 & 1 & 7 & 3 & 3 \\
PK30-136 X IC-9 & 0 & 3 & 3 & 8 & 1 \\
Arrivate X PK30-136 & 0 & 0 & 1 & 1 & 1 \\
CI5791 X Igri & 0 & 2 & 0 & 2 & 0 \\
Arabi Abiad X Arrivate & 0 & 1 & 0 & 2 & 0 \\
Total & 1 & 7 & 11 & 16 & 5 \\
\hline
\end{tabular}

*Based on a scale described by Delogu et al (1989).

\section{Materials and Methods}

\section{Plant material}

A total of 40 out of 270 barley double haploid linesproduced according to Kasha and Kao (1970) were screened under preliminary field experiments based on desirable agronomic characteristics and evaluated inthis study (Table 1). These lines were produced through five resistant-by-susceptible barley crosses made between six parents possessing different BLS reactions. Arabi Abiad is a Syrian local cultivar, PK130-36 is a Pakistan cultivar, Arrivate was received from USA, IC-9 is a new cultivar developed at ICARDA (International Center for Agricultural Research in Dry Areas), CI5791 is an Ethiopian cultivar, and Igri is a German cultivar. Briefly, spikes were manually emasculated and pollinated with fresh pollen. Pollinated spikes were treated with 2,4-dichlorophenoxyacetic acid (2,4-D). Tillers were collected from donor plants when most microspores were at mid- to late-uninucleate stage of development. Then they were placed in Hoagland's salt solution and stored at $4{ }^{\circ} \mathrm{C}$ in the dark for 21 days. Anthers were excised and transferred to FW culture medium (Arabi et al. 2005). Haploid plants were vernalized for 8 weeks. Subsequently, haploids were treated with colchicine solution for chromosome doubling (Subrahmanyam and Kasha 1975).

\section{Inoculum preparation}

The most Syrian virulent isolate Sy3 (Arabi et al. 2004) was used in this study. The fungus was grown on potato dextrose agar (PDA, DIFCO, Detroit, MI, USA) and incubated for 7 days at $20 \pm 1{ }^{\circ} \mathrm{C}$ in the darkness. Inoculation was carried out using the modified technique of Hammouda (1986). Seeds were surface-sterilized in 2\% sodium hypochlorite for $5 \mathrm{~min}$, dried for 3-4 h, then placed on 8-day-old mycelial culture growing on PDA medium in Petri dishes and incubated at $6{ }^{\circ} \mathrm{C}$ for 14 days in the dark. As a control, seeds were incubated on PDA medium alone.

\section{Field trials}

Inoculated and un-inoculated seeds of the DH lines and parents were planted under field conditions in Syria, at a site of $970 \mathrm{~m}$ altitude (550 mm rainfall average) in a randomized complete block design, with three replicates. The location of the experiment was chosen to be favorable for the development of BLS disease, since P. graminea infects barley in this location annually. Plot area was $1 \mathrm{x} 1$ $\mathrm{m}$ with a $1 \mathrm{~m}$ buffer. Each plot consisted of 5 rows $25 \mathrm{~cm}$ apart with 50 seeds sown per row. Experimental design, cultural practices and mist irrigation were as previously described (Arabi et al. 2004).

\section{BLS assessments}

Incidence and severity were estimated visually at several systematically selected sampling sites. Incidence $(I)$ was recorded as the proportion of diseased plants (number of plants with non-zero severity divided by the total number of plants sampled). Severity $(S)$ was recorded as infected leaf area per plant expressed as a proportion of the total area using a scale described by Delogu et al. (1989) where; highly resistant $(H R)(0-5 \%$ of infected plants), resistant $(R)(6-11 \%)$, moderately resistant $(M R)$ (12-26\%), susceptible (S) (27-78\%) and highly susceptible (HS) (79-100\% of infected plants).

\section{Yield estimation}

Three central rows of each replicate plot were harvested at maturity stage to measure grain yield (g/plant).

\section{Statistical analyses}

Data was subjected to analysis of variance using the STAT-ITCF statistical programme (2nd version). Differences between means were evaluated for significance by using Newman-Keuls test at 5\% probability level (Anonymous 1988). For all the experiments data, each pair of $I$ and $S$ values from each sampling site was considered an observation for data analysis. The data were edited to remove observations with no diseased plants (i.e., $I=0$ and $S=0$ ), since the $I-S$ relationship is only defined when 


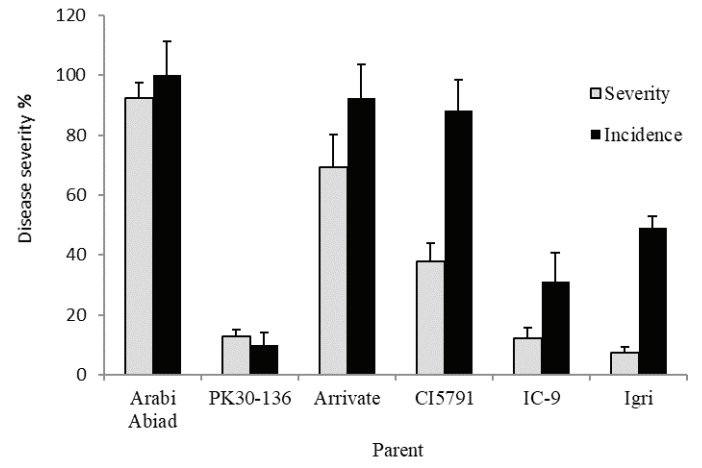

Figure 1. Frequency of LBS reactions incited on the barley parents (Arabi Abiad, Arrivate, CI5791, PK36-130, IC-9 and Igri) under field artificial conditions. Error bars are representative of the standard error (Mean \pm SD; $n=3$ ).

disease is present. The assumption of coincidence of the regression lines was tested using the ANCOVA procedure implemented in the software package Statistica 6.1.

\section{Results and Discussion}

In this present investigation, six barley parents with different resistance levels to BLS infections were used. As shown in Figure 1, the highest mean incidence and severity were recorded in parents cvs. Arrivate and Arabi Abiad, whereas, the lowest was found in the resistant parents cvs. PK30-136 and IC-9.

Data demonstrated that the distribution of BLS resistance type of the progenies can be observed in transgressive segregation toward greater resistance and susceptibility occurred in each of the crosses (Fig. 2; Table 1). However, according to a scale described by Delogu et al. (1989), the reactions of the 40 progeny lines to BLS under field tests were classified into five groups; 1 line as highly resistant, 7 resistant, 11 moderate, 16 susceptible and 5 highly susceptible (Table 1). However, significant differences $(P<0.05)$ in mean severity values were detected among different lines, and a continuum of genotypic reactions to the virulent strain SY3 from highly resistant to highly susceptible was observed (Table 2). On the other hand, significant differences $(P<0.05)$ in mean yield values were found among lines, with values being consistently higher in the susceptible ones (Table 2).

The data showed that B08-AS-5 line was highly resistant, and lines (B08-AS-12, 19, 20, 29, 35, 37 and 39) were resistant, whereas lines B08-AS 1 and 3 were the most susceptible lines (Table 2). The other lines had BLS ratings that ranged between moderately resistant and susceptible. On the other hand, Figure 3 shows that BLS severity increased linearly as incidence increased $(r=$
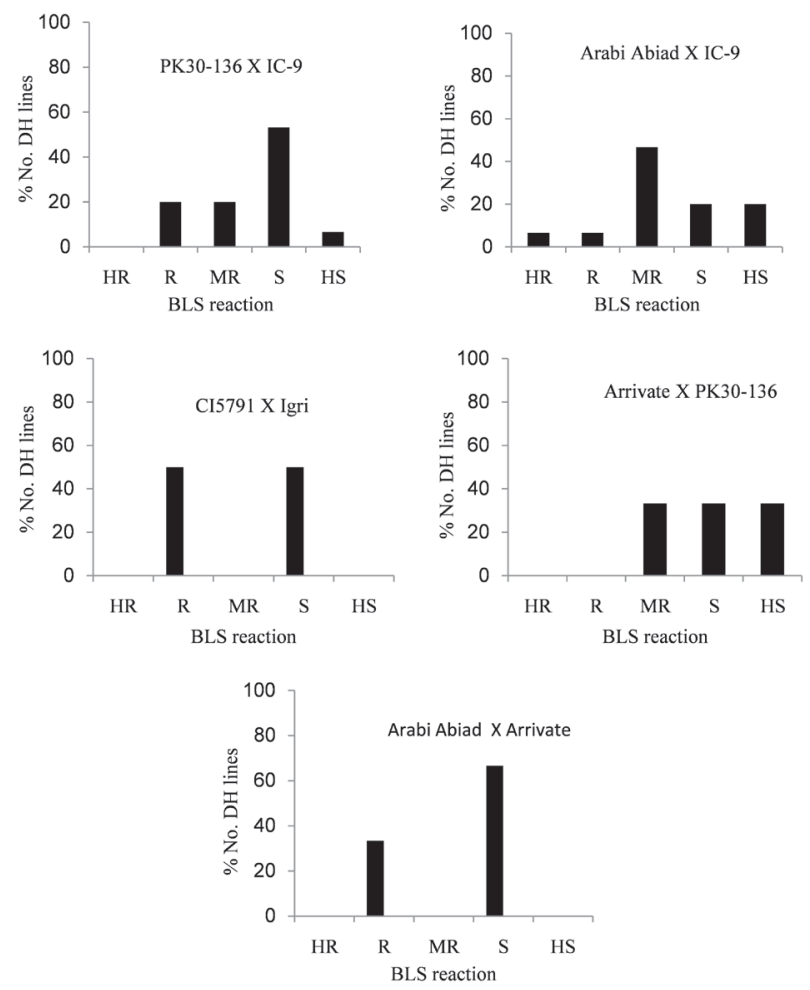

Figure 2. Distribution of BLS reactions which were highly resistant $(H R)$, resistant $(R)$, moderately resistant $(M R)$, susceptible $(S)$, and highly susceptible (HS) from the double haploid (DH) lines in the field experiments. Data were obtained from five crosses of barley parent.

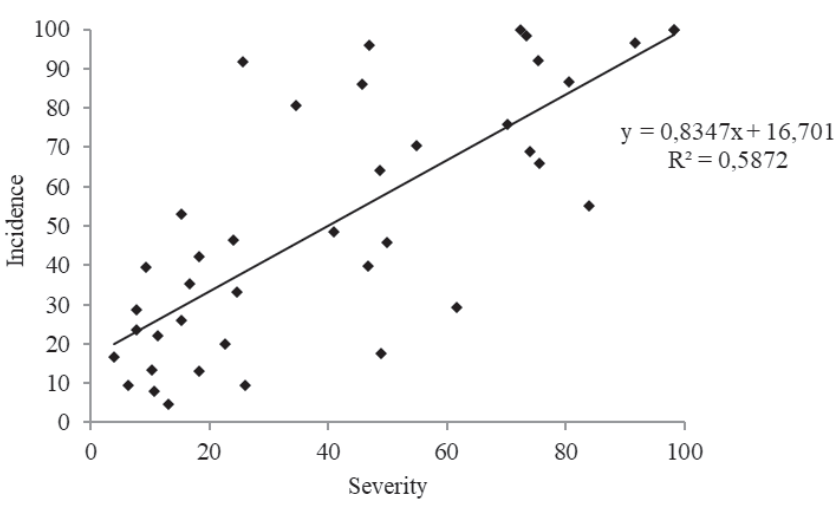

Figure 3. Incidence ( $l$; proportion of diseased plants) and severity (S; proportion of plants showing disease symptoms) of barley leaf stripe under field artificial conditions. Data points shown represent many hidden observations.

\section{$0.76, P<0.001)$.}

In this work, barley lines varied greatly in resistance to BLS. However, the resistant cultivars to BLS may in fact have various resistance response to the spread of the fungus within the infected plants hence, for any given 
Arabi et al.

Table 2. Mean leaf stripe disease incidence (I) and severity (S) and yield of the barley lines under field conditions.

\begin{tabular}{|c|c|c|c|c|c|}
\hline Cross & No. & Lines & $S$ & $I$ & Yield (g/plant) \\
\hline \multirow{15}{*}{ Arabi Abiad X IC-9 } & 1 & B08-AS-1 & $98.33 a$ & $100.00 a$ & $6.11 \mathrm{e}$ \\
\hline & 2 & B08-AS-2 & $13.00 \mathrm{~h}$ & $4.50 \mathrm{~h}$ & $15.58 a$ \\
\hline & 3 & B08-AS-3 & $98.33 a$ & $100.00 a$ & $7.65 \mathrm{~cd}$ \\
\hline & 4 & B08-AS-4 & $15.33 \mathrm{~g}$ & $25.96 f$ & $10.13 \mathrm{bcd}$ \\
\hline & 5 & B08-AS-5 & $4.00 \mathrm{~h}$ & $16.56 \mathrm{~g}$ & $12.98 \mathrm{bcd}$ \\
\hline & 6 & B08-AS-6 & $16.66 \mathrm{~g}$ & $35.26 \mathrm{e}$ & $12.09 \mathrm{bcd}$ \\
\hline & 7 & B08-AS-7 & $26.00 f$ & $9.43 \mathrm{~g}$ & $11.9 \mathrm{bcd}$ \\
\hline & 8 & B08-AS-8 & $61.66 d$ & $29.26 f$ & $7.40 \mathrm{~d}$ \\
\hline & 9 & B08-AS-9 & $48.66 \mathrm{e}$ & $64.03 c$ & $10.57 \mathrm{bcd}$ \\
\hline & 10 & B08-AS-10 & $24.00 \mathrm{~g}$ & $46.53 d$ & $10.48 \mathrm{bcd}$ \\
\hline & 11 & B08-AS-11 & $84.50 \mathrm{~b}$ & $55.16 d$ & $7.27 d$ \\
\hline & 12 & B08-AS-12 & $7.66 \mathrm{~h}$ & $28.66 f$ & $10.12 \mathrm{bcd}$ \\
\hline & 13 & B08-AS-13 & $15.33 \mathrm{~g}$ & $52.90 d$ & $10.9 \mathrm{bcd}$ \\
\hline & 14 & B08-AS-14 & $24.66 \mathrm{~g}$ & $33.30 \mathrm{e}$ & $10.02 \mathrm{bcd}$ \\
\hline & 15 & B08-AS-15 & $74.00 \mathrm{c}$ & $68.83 c$ & $9.5 \mathrm{bcd}$ \\
\hline \multirow{15}{*}{ PK30-136 X IC-9 } & 16 & B08-AS-16 & $49.00 \mathrm{e}$ & $17.63 \mathrm{~g}$ & $9.97 b c d$ \\
\hline & 17 & B08-AS-17 & $18.33 \mathrm{~g}$ & $13.20 \mathrm{~g}$ & $10.20 \mathrm{bcd}$ \\
\hline & 18 & B08-AS-18 & $75.66 \mathrm{~b}$ & $65.90 c$ & $9.68 \mathrm{bcd}$ \\
\hline & 19 & B08-AS-19 & $9.33 \mathrm{~h}$ & $39.46 \mathrm{e}$ & $10.02 \mathrm{bcd}$ \\
\hline & 20 & B08-AS-20 & $6.33 \mathrm{~h}$ & $9.50 \mathrm{~g}$ & $16.10 a$ \\
\hline & 21 & B08-AS-21 & $41.00 \mathrm{e}$ & $48.50 d$ & $8.93 \mathrm{bcd}$ \\
\hline & 22 & B08-AS-22 & $55.00 d$ & $70.33 c$ & $7.50 \mathrm{~cd}$ \\
\hline & 23 & B08-AS-23 & $34.66 f$ & $80.73 b$ & $8.83 \mathrm{bcd}$ \\
\hline & 24 & B08-AS-24 & $25.66 f$ & $91.83 a$ & $8.27 \mathrm{bcd}$ \\
\hline & 25 & B08-AS-25 & $45.66 \mathrm{e}$ & $86.03 b$ & $8.03 \mathrm{bcd}$ \\
\hline & 26 & B08-AS-26 & $80.50 \mathrm{~b}$ & $86.66 b$ & $8.31 \mathrm{bcd}$ \\
\hline & 27 & B08-AS-27 & $75.33 b$ & $92.13 a$ & $8.30 \mathrm{bcd}$ \\
\hline & 28 & B08-AS-28 & $47.00 \mathrm{e}$ & $96.00 a$ & $7.53 \mathrm{~cd}$ \\
\hline & 29 & B08-AS-29 & $7.66 \mathrm{~h}$ & $23.66 f$ & $13.72 \mathrm{bcd}$ \\
\hline & 30 & B08-AS-30 & $18.33 \mathrm{~g}$ & $42.10 \mathrm{e}$ & $13.77 \mathrm{bcd}$ \\
\hline \multirow{3}{*}{ Arrivate X PK30-136 } & 31 & B08-AS-31 & $22.66 \mathrm{~g}$ & $20.10 f$ & $10.12 \mathrm{bcd}$ \\
\hline & 32 & B08-AS-32 & $46.66 \mathrm{e}$ & $39.83 e$ & $10.9 \mathrm{bcd}$ \\
\hline & 33 & B08-AS-33 & $91.83 a$ & $96.60 a$ & $6.53 \mathrm{ef}$ \\
\hline \multirow{4}{*}{ CI7591 X Igri } & 34 & B08-AS-34 & $50.00 \mathrm{e}$ & $45.93 d$ & $9.17 \mathrm{bcd}$ \\
\hline & 35 & B08-AS-35 & $10.66 \mathrm{~h}$ & $7.86 \mathrm{~g}$ & $15.78 a$ \\
\hline & 36 & B08-AS-36 & $70.20 c$ & $75.76 b$ & $7.51 \mathrm{~cd}$ \\
\hline & 37 & B08-AS-37 & $10.33 \mathrm{~h}$ & $13.40 \mathrm{~g}$ & $15.12 \mathrm{a}$ \\
\hline \multirow[b]{2}{*}{ Arabi Abiad X Arrivate } & 38 & B08-AS-38 & $72.33 c$ & 100.00a & 6.60 ef \\
\hline & $\begin{array}{l}39 \\
40\end{array}$ & $\begin{array}{l}\text { B08-AS-39 } \\
\text { B08-AS-40 }\end{array}$ & $\begin{array}{l}11.33 \mathrm{~h} \\
73.33 \mathrm{c}\end{array}$ & $\begin{array}{l}22.00 f \\
98.33 a\end{array}$ & $\begin{array}{l}14.89 a \\
6.10 \mathrm{e}\end{array}$ \\
\hline
\end{tabular}

*Values within a column followed by different letters are significantly different

incidence value, a wide range of severity values may be observed across cultivars. Our findings agree with the results of Paul et al. (2005) for fusarium head blight on winter wheat. McRoberts et al. (2003) reported that the I-S relationship might be used to draw conclusions about the relative rate of disease increase among cultivars with different levels of resistance. On the other hand, data showed that the average response to BLS disease differed with the differences in the susceptibility level of $\mathrm{DH}$ lines (Table 2). These results in a good agreement with those obtained by Delogu et al (1989). However, Table 2 demonstrated in general that when I and $\mathrm{S}$ values were high the mean yield per plant was low (lines B08-AS-1, 3, 26, 33, 36, 38 and 40). Moreover, DH lines with low 
disease levels were associated with high yield although some of them not the highest yielding. Gaunt and Wright (1992) reported that the effect of BLS on grain yield may be attributed to reduced area of photosynthetically active tissue enhances respiration and transpiration or to disturbance in translocation of assimilates to the spike.

One of the major objectives of the Syrian barley breeding program is to develop high-yielding cultivars with resistance to BLS disease through the transfer of genes from resistant sources. The population of crosses CI5791/ Igri and PK30-136 /IC-9 will be used for mapping genes associated with BLS resistance. Some lines from this cross were recovered with a high degree of resistance to this disease. These will be tested in further work under multilocation trials to test their stability and adaptability.

Additionally, the data demonstrated that barley lines have enough variability for infection response to BLS pathogen. Therefore, inclusion of this diverse germplasm in the barley breeding program might increase the dominance effect and epistatic variations controlling quantitative traits such as BLS resistance (Çetin et al. 1995; Bayraktar and Akan 2012). These would also lead to extend segregation for various traits and in obtaining useful recombinants/transgressive segregants in the further generations. However, crossbreeding with a wide range of modern varieties accompanied with selection under field conditions will lead to an accumulation of partial resistances again. As partial resistances have a complex biological background, one should concentrate on the context in which the disease occurs. Barley plants will not be infected, if they survive cold temperatures in the juvenile stage (Prasad et al. 1976). The surprising high rates of resistances in DH lines derived from Ethiopia and Pakistan parents were recorded. This may be since in Ethiopia and Pakistan, barley often is cultivated at higher elevation, i.e. at cooler temperatures.

This study showed that the barley breeding lines had diversity for infection response to BLS pathogen. Eight promising sources of resistance with high yield per plant were identified that could be considered as possible donors in further barley breeding programs. In addition, a positive relationship between proportion of diseased plants and the proportion of infected leaf area was detected, however, characterizing the functional relationship between $I$ and $S$ is still highly important, since through this relationship scientists can identify cultivars with large or small severities for a given incidence (McRoberts et al. 2003), or through covariance analysis (when there are several pairs of $I-S$ points for each cultivar), identify cultivars with an unusual $I-S$ relationship compared with others.

\section{Acknowledgements}

The authors wish to thank the Director General of AECS and the Head of the Molecular Biology and Biotechnology Department for their continuous support throughout this work.

\section{References}

Anonymous (1988) STAT-ITCF, Programme, MICROSTA, realized by ECOSOFT, $2^{\text {nd }}$ Version, Institut Technique des Cereals et des Fourrages Paris, pp.55.

Arabi MIE, Jawhar M, Al-Safadi B, MirAli N (2004) Yield responses of barley to leaf stripe (Pyrenophora graminea) under experimental conditions in southern Syria. J Phytopathol 152:519-523.

Arabi MIE, Al-Safadi B, Jawhar M. Mir-Ali N (2005) Enhancement of embryogenesis and plant regeneration from barley anther culture by low doses of gamma irradiation. In Vitro Cell Dev Biol 41:762-764.

Arabi MIE, Jawhar M (2005) Barley reaction to Pyrenophora graminea based on the fungus movement. Plant Pathol 34:405-407.

Arabi MIE, Jawhar M (2010) Interrelationship between incidence and severity of leaf stripe on barley. J Plant Pathol 92:503-505.

Bayraktar H, Akan K (2012) Genetic characterization of Pyrenophora graminea isolates and the reaction of some barley cultivars to leaf stripe disease under greenhouse conditions. Tur J Agri Forest 36:329-339.

Benkorteby-Lyazidi H, Zeghar I., Hanifi-Mekliche L, Bouznad Z (2019) Barley leaf stripe disease in Algeria: evaluation of virulent Pyrenophora graminea isolates and identification of resistant Algerian barley genotypes. Tarım Bilimleri Dergisi - J Agri Sci 25:367-372.

Delogu G, Porta-Puglia AC, Vannacci G (1989) Resistance of winter barley varieties subjected to natural inoculums of Pyrenophora graminea. J Genet Breed 43:61-65.

Campbell CL, Madden LV (1990) Introduction to Plant Disease Epidemiology. John Wiley \& Sons, New York.

Carisse O, Lefebvre A, Van der Heyden H, Roberge L, Brodeur L (2013) Analysis of incidence-severity relationships for strawberry powdery mildew as influenced by cultivar, cultivar type, and production systems. Plant Dis 97:354-362.

Çelik Y, Karakaya A, Çelik Oğuz A, Mert Z, Akan K, Ergün N, Sayim I (2016) Determination of the reactions of some barley landraces and cultivars to Drechslera graminea. Med Agri Sci 29:43-47.

Çetin L, Albustan S, Düsünceli F, Tosun H, Akar T (1995) Determination of resistance of barley breeding materi- 
als developed for Central Anatolia to barley leaf stripe (Pyrenophora graminea). In: VII. Türkiye Fitopatoloji Kongresi, Adana, p. 126.

Delogu G, Porta-Puglia A C., Vannacci G (1989) Resistance of winter barley varieties subjected to natural inoculums of Pyrenophora graminea. J Genet Breed 43:61-65.

Gaunt RF, Wright AC (1992) Disease yield relationship in barley II. Contribution of stored stem reserves to grain filling. Plant Pathol 41:688-701.

Hammouda AM (1986) Modified technique for inoculation in leaf stripe of barley. Acta Phytopathol Entomol Hung 21:255-259.

Kasha KJ, Kao KN (1970) High frequency haploid production in barley (Hordeum vulgare L.). Nature 225:874-876.

McRoberts N, Hughes G, Madden LV (2003) The theoretical basis and practical application of relationships between different disease intensity measures in plants. Ann Appl Biol 142:191-211.

Mathre DE (1997) Compendium of barley diseases. 2nd ed. APS Press, St Paul.
Nielsen BJ (2012) Screening for resistance to leaf stripe (Pyrenophora graminea) in barley. In Yahyaoui AH, Brader L, Tekauz A, Wallwork H, Steffenson B, Eds, Proceedings of the $2^{\text {nd }}$ International Workshop on Barley Leaf Blights, 7-11 April 2012, ICARDA, Aleppo, Syria. ICARDA, Aleppo, 277-280.

Prasad MN, Leonard KJ, Murphy CF (1976) Effects of temperatures and soil water potential on expression of leaf stripe incited by Helminthosporium gramineum. Phytopathology 66:631-634.

Paul PA, El-Allaf SM, Lipps PE, Madden LV (2005) Relationships between incidence and severity of fusarium head blight on winter wheat in Ohio. Phytopathology 95:1049-1060.

Platenkamp R (1976) Investigation on the infection pathway of Drechslera graminea in germinating barley. K Vet Landbohoejsk Arsskr 1976:49-64.

Subrahmanyam NC, Kasha KJ (1975) Chomosome doubling of barley haploids by nitrous oxide and colchicines treatments. Can J Genet Cytol 17:573-583. 